\title{
Complete genome sequence of Bacillus amyloliquefaciens subsp. plantarum S499, a rhizobacterium that triggers plant defences and inhibits fungal phytopathogens
}

\author{
Giulia Molinatto ${ }^{\mathrm{a}, 1}$, Gerardo Puopolo ${ }^{\mathrm{a}, *, 1}$, Paolo Sonego ${ }^{\mathrm{b}}$, Marco Moretto ${ }^{\mathrm{b}}$, \\ Kristof Engelen $^{\mathrm{b}}$, Carlo Viti ${ }^{\mathrm{c}}$, Marc Ongena ${ }^{\mathrm{d}}$, Ilaria Pertot ${ }^{\mathrm{a}}$ \\ ${ }^{a}$ Department of Sustainable Agro-Ecosystems and Bioresources, Research and Innovation Centre, Fondazione Edmund Mach, Via E. Mach 1-38010 S. \\ Michele all'Adige, TN, Italy \\ ${ }^{\mathrm{b}}$ Department of Computational Biology, Research and Innovation Centre, Fondazione Edmund Mach, Via E. Mach 1-38010 S. Michele all'Adige, TN, Italy \\ ${ }^{\mathrm{c}}$ Department of Agrifood Production and Environmental Sciences, University of Firenze, Piazzale delle Cascine 24-50144 Florence, Italy \\ d Microbial Processes and Interactions Research Unit, Gembloux Agro-Bio Tech, University of Liège, Passage des Déportés 2-5030 Gembloux, Belgium
}

\section{A R T I C L E I N F O}

\section{Article history:}

Received 21 July 2016

Received in revised form

17 September 2016

Accepted 23 September 2016

\section{Keywords:}

Bacillus amyloliquefaciens subsp. plantarum

PacBio RS II

Rhizosphere

Lipopeptides

Amylolysin

Amylocyclicin

\begin{abstract}
A B S T R A C T
Bacillus amyloliquefaciens subsp. plantarum S499 is a plant beneficial rhizobacterium with a good antagonistic potential against phytopathogens through the release of active secondary metabolites. Moreover, it can induce systemic resistance in plants by producing considerable amounts of surfactins. The complete genome sequence of B. amyloliquefaciens subsp. plantarum S499 includes a circular chromosome of $3,927,922 \mathrm{bp}$ and a plasmid of $8,008 \mathrm{bp}$. A remarkable abundance in genomic regions of putative horizontal origin emerged from the analysis. Furthermore, we highlighted the presence of genes involved in the establishment of interactions with the host plants at the root level and in the competition with other soilborne microorganisms. More specifically, genes related to the synthesis of amylolysin, amylocyclicin, and butirosin were identified. These antimicrobials were not known before to be part of the antibiotic arsenal of the strain. The information embedded in the genome will support the upcoming studies regarding the application of B. amyloliquefaciens isolates as plant-growth promoters and biocontrol agents.
\end{abstract}

(C) 2016 Elsevier B.V. All rights reserved.

\section{Introduction}

Since its isolation from a cultivated soil in the Iturie region (Democratic Republic of Congo; Delcambe, 1965), the rhizobacterium Bacillus amyloliquefaciens subsp. plantarum S499 (available at BCCM/LMG Bacteria Collection, LMG 29676) has been extensively described due to its plant beneficial properties shown in greenhouse and field trials (Nihorimbere et al., 2010; Pertot et al., 2013). The protection provided by S499 against phytopathogens relies on its potential to produce multiple antimicrobial metabolites (Cawoy et al., 2015) and on its ability to induce systemic resistance in plants (Ongena et al., 2005a,b, 2007). This strain is an excellent producer of the surfactin-type lipopeptide, which not only contributes to the high rhizosphere competence of the bacterium but which also acts as the main elicitor of host immunity (Cawoy et al., 2014). It most probably explains why in a comparative study, which included 16 root-associated Bacillus isolates, S499 was the most efficient in disease reduction (Cawoy et al., 2014). For these reasons, S499 has often been used as model to investigate the impact of biotic and abiotic factors on rhizosphere fitness and antibiotic production in B. amyloliquefaciens, but also to study the molecular interactions established with the host plant (Debois et al., 2015; Henry et al., 2011; Nihorimbere et al., 2012; Pertot et al., 2013). Furthermore, expression of its biocontrol-related antibiome has been characterised in details, both in vitro and in planta (Debois et al., 2014). The availability of the S499 complete genome can provide an additional tool for in-depth investigation of the mechanisms involved in biocontrol of plant diseases and be the basis for the development of novel more effective biofungicides based on bacteria belonging to B. amyloliquefaciens subsp. plantarum.

\footnotetext{
* Corresponding author.

E-mail address: gerardo.puopolo@fmach.it (G. Puopolo).

1 These authors contributed equally to this work.
} 
Table 1

Features of Bacillus amyloliquefaciens subsp. plantarum S499 genome.

\begin{tabular}{lll}
\hline Features & Chromosome & Plasmid \\
\hline Genome size (bp) & $3,927,922$ & 8,008 \\
G + C content (\%) & 46.6 & 40.40 \\
Total predicted CDS & 3,974 & 7 \\
rRNA operons & 24 & - \\
tRNA genes & 81 & - \\
Insertion sequence & 1 & - \\
Phage-associated genes & 154 & - \\
\hline
\end{tabular}

a CDS: Coding DNA Sequences.

\section{Materials and methods}

\subsection{DNA extraction and genome sequencing}

Genomic DNA was extracted from S499 cultures using a PureLink Genomic DNA Mini Kit (Thermo Fisher Scientific, Invitrogen, USA) according to the manufacturer's instructions. A 10-kb PacBio ${ }^{\circledR}$ RS II single-molecule real-time (SMRT) cell (Chin et al., 2013) was used to sequence the whole genomic DNA of S499 through PacBio technology at Baseclear B.V. (Leiden, Netherlands).

\subsection{Genome assembly and annotation}

Assembly of subreads obtained with the PacBio ${ }^{\circledR}$ RS II SMRT was carried out using the RS hierarchical genome assembly process (HGAP) protocol version 3.0, as available in SMRT Portal v2.0 (https://github.com/PacificBiosciences/BioinformaticsTraining/wiki/HGAP-in-SMRT-Analysis). The SMRT Portal was configured and used with a public machine image that Pacific Biosciences maintains and upgrades on Amazon Cloud (https:// github.com/PacificBiosciences/Bioinformatics-Training/wiki/ \%22Installing\%22-SMRT-Portal-the-easy-way-Launching-ASMRT-Portal-AMI). Whole genome assembly was achieved with a comparative method, which combined de novo assembly and mapping through the MAUVE aligner tool (Darling et al., 2010). Annotation was carried out using Rapid Annotation Subsystem Technology (RAST; Aziz et al., 2008). Tandem repeats were detected with Tandem Repeats Finder (Benson, 1999) and genomic islands were screened using IslandViewer (Dhillon et al., 2013; Langille and Brinkman, 2009). IS Finder (Siguier et al., 2006) and PHAST (Zhou et al., 2011) were used to identify insertion sequences and prophage regions. Genome mining for bioactive secondary metabolites was performed via antiSMASH 3.0 (Weber et al., 2015).

\section{Results and discussion}

The genetic equipment of S499 consists of a 3,927,922 bp circular chromosome and an 8,008 bp plasmid (Fig. 1). The plasmid contains only seven coding DNA sequences (CDS) while the circular chromosome has 3,974 CDS, and 106 predicted RNA genes (Table 1). The circular chromosome includes 99 tandem repeats and one insertion sequence element of $1,275 \mathrm{bp}$ identified as "ISBsu1", encoding a transposase and a tail length tape measure protein. Furthermore, we detected four prophage regions, containing 154 putative phage-related genes. Screening for genomic islands revealed the presence of five additional regions of hypothetical horizontal origin, which include the CDS involved in antibiotic resistance, detoxification and stress responses (Table 1 ). This finding could reflect the S499 adaptation to its natural soil ecosystem. In such habitat, the evolution of bacterial populations continuously exposed to environmental stresses could largely depend on a high rate of horizontal gene exchanges (Aminov, 2011).

Through RAST classification into subsystems (Table 2), we highlighted the importance of the coding portion of the S499 genome
Table 2

Distribution of Bacillus amyloliquefaciens subsp. plantarum S499 coding DNA sequences (CDS) in subsystems according to RAST Server.

\begin{tabular}{ll}
\hline Subsystem & CDS \\
\hline Cofactors, Vitamins, Prosthetic Groups, Pigments & 229 \\
Cell Wall and Capsule & 138 \\
Virulence, Disease and Defense & 60 \\
Potassium metabolism & 9 \\
Photosynthesis & 0 \\
Miscellaneous & 47 \\
Phages, Prophages, Transposable elements, Plasmids & 25 \\
Membrane Transport & 69 \\
Iron acquisition and metabolism & 30 \\
RNA Metabolism & 155 \\
Nucleosides and Nucleotides & 114 \\
Protein Metabolism & 162 \\
Cell Division and Cell Cycle & 55 \\
Motility and Chemotaxis & 86 \\
Regulation and Cell signaling & 64 \\
Secondary Metabolism & 6 \\
DNA Metabolism & 105 \\
Fatty Acids, Lipids, and Isoprenoids & 138 \\
Nitrogen Metabolism & 31 \\
Dormancy and Sporulation & 117 \\
Respiration & 74 \\
Stress Response & 108 \\
Metabolism of Aromatic Compounds & 12 \\
Amino Acids and Derivatives & 444 \\
Sulfur Metabolism & 39 \\
Phosphorus Metabolism & 31 \\
Carbohydrates & 414 \\
\hline
\end{tabular}

that supports bacterial development on roots. Indeed, as much as $15 \%$ of the classified CDS were assigned to categories related to the ability of S499 to effectively colonize plant roots and produce secondary metabolites responsible for the control of phytopathogens ("Motility and Chemotaxis", "Membrane Transport", "Virulence, Disease and Defense", "Secondary Metabolism" and "Stress Responses"). Regarding the intrinsic plant growth promotion function of the strain (Nihorimbere et al., 2010), we assessed the presence of the genes necessary for synthesis of auxin, phytase, and volatile compounds (e.g. 2,3-butanediol and acetoin) known to be implicated in this activity (Idriss et al., 2002; Ryu et al., 2004; Table 2). In the context of phytopathogen biocontrol, the antiSMASH analysis allowed to identify gene clusters encoding the enzymatic machinery for synthesis of nonribosomal peptides (surfactins, iturins, fengycins, bacillibactin, and bacilysin) and polyketides (bacillaene, difficidin, and macrolactin, Table 3). The antiSMASH analysis identified additional genes related to the production of other antimicrobials, such as the lantibiotic amylolysin (Arguelles-Arias et al., 2013), the bacteriocin amylocyclicin (Scholz et al., 2014), and the aminoglycoside antibiotic butirosin (Llewellyn et al., 2007), which have not been detected using chemical analysis in culture media of the strain to date (Debois et al., 2014).

The genomic features of S499 thus clearly reflect its rootassociated lifestyle and its biocontrol potential. Most importantly, the complete genome of this efficient and peculiar Bacillus strain is being used for developing transcriptomic studies with the aim of understanding how the antibiome expression profile in this bacterium is modulated upon interaction with a variety of host plants and with the numerous competitors present in the rhizosphere microbiome.

\section{Nucleotide sequence accession number}

The complete nucleotide genome sequence of $B$. amyloliquefaciens subsp. plantarum S499 has been deposited at 

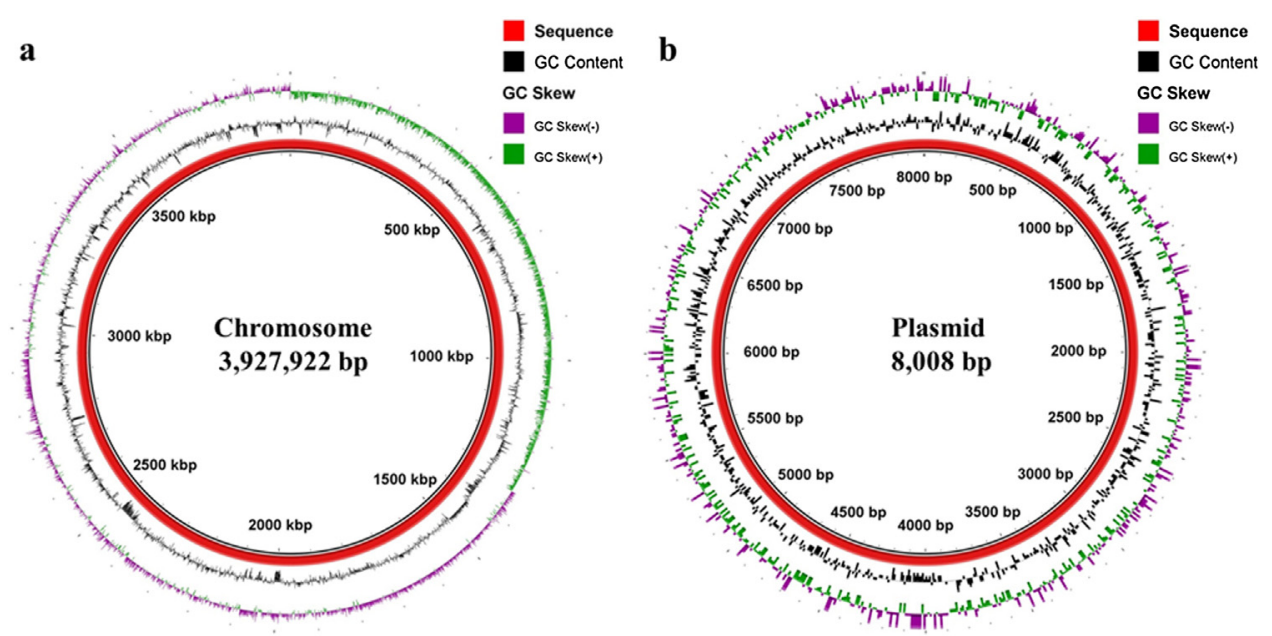

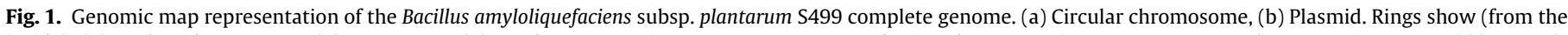

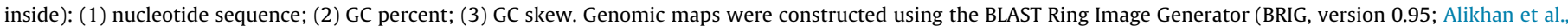
2011).

Table 3

Identification of gene clusters potentially involved in the synthesis of secondary metabolites by Bacillus amyloliquefaciens subsp. plantarum S499.

\begin{tabular}{|c|c|c|c|c|}
\hline Cluster $^{\mathrm{a}}$ & Type $^{\mathrm{b}}$ & From $^{c}$ & $\mathrm{To}^{\mathrm{c}}$ & Secondary metabolite ${ }^{\mathrm{d}}$ \\
\hline 1 & Trans-AT PKS cluster & 852,198 & 952,636 & Difficidin \\
\hline 2 & Type III PKS cluster & $1,068,971$ & $1,110,071$ & Unknown \\
\hline 3 & Terpene & $1,160,436$ & $1,182,319$ & Unknown \\
\hline 4 & Nrps-Transatpks & $1,204,945$ & $1,342,774$ & $\begin{array}{l}\text { Fengycin } \\
\text { Iturin }\end{array}$ \\
\hline 5 & Transatpks-Nrps & $1,399,613$ & $1,502,314$ & Bacillaene \\
\hline 6 & Transatpks & $1,728,554$ & $1,814,435$ & Macrolactin \\
\hline 7 & Lantipeptide & $1,981,950$ & $2,010,839$ & Amylolysin \\
\hline 8 & Terpene & $2,169,549$ & $2,190,289$ & Unknown \\
\hline 9 & Other types of PKS cluster & $2,272,301$ & $2,313,545$ & Butirosin \\
\hline 10 & Nonribosomal peptide synthetase cluster & $2,589,001$ & $2,654,407$ & Surfactin \\
\hline 11 & Nrps-Bacteriocin & $3,025,102$ & $3,091,892$ & $\begin{array}{l}\text { Bacillibactin } \\
\text { Amylocyclin }\end{array}$ \\
\hline 12 & Other & $3,599,548$ & $3,640,966$ & Bacilysin \\
\hline
\end{tabular}

a Clusters identified using default settings of antiSMASH 3.0.

b Class of gene cluster according to antiSMASH 3.0.

c Location of gene clusters in the B. amyloliquefaciens subsp. plantarum S499 genome.

d Secondary metabolites potentially produced based on the gene clusters.

DDBJ/EMBL/GenBank under the accession numbers CP014700 (chromosome) and CP014701 (plasmid).

\section{Acknowledgments}

This research was supported by the EU project INNOVA (subprogram: FP7-PEOPLE-2012-IAPP, grant agreement: 324416). M. Ongena is Senior Research Associate at the F.R.S.-FNRS (Fonds National de la Recherche Scientifique) in Belgium.

\section{References}

Alikhan, N.F., Petty, N.K., BenZakour, N.L., Beatson, S.A., 2011. BLAST Ring Image Generator (BRIG): simple prokaryote genome comparisons. BMC Genomics 12 , 402, http://dx.doi.org/10.1186/1471-2164-12-402.

Aminov, R.I., 2011. Horizontal gene exchange in environmental microbiota. Front. Microbiol. 2, 158, http://dx.doi.org/10.3389/fmicb.2011.00158.

Arguelles-Arias, A., Ongena, M., Devreese, B., Terrak, M., Joris, B., Fickers, P., 2013. Characterization of amylolysin, a novel lantibiotic from Bacillus amyloliquefaciens GA1. PLoS One 8, e83037, http://dx.doi.org/10.1371/journal. pone.0083037.

Aziz, R.K., Bartels, D., Best, A.A., DeJongh, M., Disz, T., Edwards, R.A., Formsma, K., Gerdes, S., Glass, E.M., Kubal, M., Meyer, F., 2008. The RAST Server: rapid annotations using subsystems technology. BMC Genomics 9, 75, http://dx.doi. org/10.1186/1471-2164-9-75.

Benson, G., 1999. Tandem repeats finder: a program to analyze DNA sequences. Nucleic Acids Res. 27, 573, http://dx.doi.org/10.1093/nar/27.2.573.
Cawoy, H., Mariutto, M., Henry, G., Fisher, C., Vasilyeva, N., Thonart, P., Dommes, J., Ongena, M., 2014. Plant defense stimulation by natural isolates of Bacillus depends on efficient surfactin production. Mol. Plant Microbe Interact. 27, 87-100, http://dx.doi.org/10.1094/MPMI-09-13-0262-R.

Cawoy, H., Debois, D., Franzil, L., De Pauw, E., Thonart, P., Ongena, M., 2015. Lipopeptides as main ingredients for inhibition of fungal phytopathogens by Bacillus subtilis amyloliquefaciens. Microb. Biotechnol. 8, 281-295, http://dx. doi.org/10.1111/1751-7915.12238.

Chin, C.S., Alexander, D.H., Marks, P., Klammer, A.A., Drake, J., Heiner, C., Clum, A Copeland, A., Huddleston, J., Eichler, E.E., Turner, S.W., Korlach, J., 2013. Nonhybrid, finished microbial genome assemblies from long-read SMRT sequencing data. Nat. Methods 10, 563-569, http://dx.doi.org/10.1038/nmeth. 2474.

Darling, A.E., Mau, B., Perna, N.T., 2010. ProgressiveMauve: multiple genome alignment with gene gain, loss and rearrangement. PLoS One 5, e11147, http:// dx.doi.org/10.1371/journal.pone.0011147.

Debois, D., Jourdan, E., Smargiasso, N., Thonart, P., De Pauw, E., Ongena, M., 2014 Spatiotemporal monitoring of the antibiome secreted by Bacillus biofilms on plant roots using MALDI mass spectrometry imaging. Anal. Chem. 86, 4431-4438, http://dx.doi.org/10.1021/ac500290s.

Debois, D., Fernandez, O., Franzil, L., Jourdan, E., Brogniez, A., Willems, L., Clément, C., Dorey, S., De Pauw, E., Ongena, M., 2015. Plant polysaccharides initiate underground crosstalk with bacilli by inducing synthesis of the immunogenic lipopeptide surfactin. Environ. Microbiol. Rep. 7, 570-582, http://dx.doi.org/10. 1111/1758-2229.12286.

Delcambe, L., L'Iturine, I., 1965. Préparation: purification et poids moléculaire. Bull. Soc. Chim. Belg. 74, 315-328.

Dhillon, B.K., Chiu, T.A., Laird, M.R., Langille, M.G., Brinkman, F.S., 2013. IslandViewer update: improved genomic island discovery and visualization. Nucleic Acids Res. 41, W129-W132, http://dx.doi.org/10.1093/nar/gkt394. 
Henry, G., Deleu, M., Jourdan, E., Thonart, P., Ongena, M., 2011. The bacterial lipopeptide surfactin targets the lipid fraction of the plant plasma membrane to trigger immune-related defence responses. Cell. Microbiol. 1311, 1824-1837, http://dx.doi.org/10.1111/j.1462-5822.2011.01664.x.

Idriss, E.E., Makarewicz, O., Farouk, A., Rosner, K., Greiner, R., Bochow, H., Richter, T., Borriss, R., 2002. Extracellular phytase activity of Bacillus amyloliquefaciens FZB45 contributes to its plant-growth-promoting effect. Microbiology 148, 2097-2109, http://dx.doi.org/10.1099/00221287-148-7-2097.

Langille, M.G., Brinkman, F.S., 2009. IslandViewer: an integrated interface for computational identification and visualization of genomic islands.

Bioinformatics 5, 664-665, http://dx.doi.org/10.1093/bioinformatics/btp030.

Llewellyn, N.M., Li, Y., Spencer, J.B., 2007. Biosynthesis of butirosin: transfer and deprotection of the unique amino acid side chain. Chem. Biol. 14, 379-386, http://dx.doi.org/10.1016/j.chembiol.2007.02.005.

Nihorimbere, V., Ongena, M., Cawoy, H., Brostaux, Y., Kakana, P., Jourdan, E., Thonart, P., 2010. Beneficial effects of Bacillus subtilis on field-grown tomato in Burundi: reduction of local Fusarium disease and growth promotion. Afr. J. Microbiol. Res. 4, 1135-1142.

Nihorimbere, V., Cawoy, H., Seyer, A., Brunelle, A., Thonart, P., Ongena, M., 2012. Impact of rhizosphere factors on cyclic lipopeptide signature from the plant beneficial strain Bacillus amyloliquefaciens S499. FEMS Microbial. Ecol. 79, 176-191, http://dx.doi.org/10.1111/j.1574-6941.2011.01208.x.

Ongena, M., Duby, F., Jourdan, E., Beaudry, T., Jadin, V., Dommes, J., Thonart, P., 2005a. Bacillus subtilis M4 decreases plant susceptibility towards fungal pathogens by increasing host resistance associated with differential gene expression. Appl. Microbiol. Biotechnol. 67, 692-698, http://dx.doi.org/10. 1007/s00253-004-1741-0.

Ongena, M., Jacques, P., Touré, Y., Destain, J., Jabrane, A., Thonart, P., 2005b. Involvement of fengycin-type lipopeptides in the multifaceted biocontrol potential of Bacillus subtilis. Appl. Microbiol. Biotechnol. 69, 29-38, http://dx. doi.org/10.1007/s00253-005-1940-3.

Ongena, M., Jourdan, E., Adam, A., Paquot, M., Brans, A., Joris, B., Arpigny, J.L., Thonart, P., 2007. Surfactin and fengycin lipopeptides of Bacillus subtilis as elicitors of induced systemic resistance in plants. Environ. Microbiol. 9 , 1084-1090, http://dx.doi.org/10.1111/j.1462-2920.2006.01202.x.

Pertot, I., Puopolo, G., Hosni, T., Pedrotti, L., Jourdan, E., Ongena, M., 2013. Limited impact of abiotic stress on surfactin production in planta and on disease resistance induced by Bacillus amyloliquefaciens S499 in tomato and bean. FEMS Microbiol. Ecol. 86, 505-519, http://dx.doi.org/10.1111/1574-6941.12177.

Ryu, C.M., Farag, M.A., Hu, C.H., Reddy, M.S., Kloepper, J.W., Paré, P.W., 2004. Bacterial volatiles induce systemic resistance in Arabidopsis. Plant Physiol. 134, 1017-1026, http://dx.doi.org/10.1104/pp.103.026583.

Scholz, R., Vater, J., Budiharjo, A., Wang, Z., He, Y., Dietel, K., Schwecke, T., Herfort S., Lasch, P., Borriss, R., 2014. Amylocyclicin, a novel circular bacteriocin produced by Bacillus amyloliquefaciens FZB42. J. Bacteriol. 196, 1842-1852, http://dx.doi.org/10.1128/JB.01474-14.

Siguier, P., Pérochon, I., Lestrade, L., Mahillon, I., Chandler, M., 2006. ISfinder: the reference centre for bacterial insertion sequences. Nucleic Acids Res. 34, D32-D36, http://dx.doi.org/10.1093/nar/gkj014.

Weber, T., Blin, K., Duddela, S., Krug, D., Kim, H.U., Bruccoleri, R., Lee, S.Y. Fischbach, M.A., Müller, R., Wohlleben, W., Breitling, R., 2015. antiSMASH 3.0-a comprehensive resource for the genome mining of biosynthetic gene clusters. Nucleic Acids Res., http://dx.doi.org/10.1093/nar/gkv437, gkv437.

Zhou, Y., Liang, Y., Lynch, K.H., Dennis, J.J., Wishart, D.S., 2011. PHAST: a fast phage search tool. Nucleic Acids Res., http://dx.doi.org/10.1093/nar/gkr485, gkr485. 